\title{
Health-Related Quality Of Life and Rearing Behavior on Migrant Children: A Before-and-After Study
}

\author{
Haiyan XING ${ }^{1 *}$, Wei YU" \\ 'Department of Nursing, School of Medicine, Shaoxing University, Zhejiang Province, China \\ ${ }^{2}$ Institute of Epidemiology, Shaoxing Keqiao District Center for Disease Control and Prevention, Zhejiang Province, China
}

Article Info

\section{Article Notes}

Received: August 31, 2020

Accepted: October 26, 2020

\section{*Correspondence:}

Dr. Haiyan XING, Department of Nursing, School of Medicine, Shaoxing University, Zhejiang Province, China; No.900,

Chengnan Avenue, Shaoxing Yuecheng District, 312000,

Zhejiang Province, China; E-mail: petrelx99@163.com.

(c) $2020 \mathrm{XING} \mathrm{H}$. This article is distributed under the terms of the Creative Commons Attribution 4.0 International License.

\section{Keywords:}

Health-related Quality of life

Rearing behavior

Migrant children
Abstract

The purpose of this study is to examine the change of Health-related quality of life (HRQOL) and rearing behavior among migrant children as well as their correlations in the city of Shaoxing, China. By cluster sampling, 149 migrant children had completed the questionnaires in 2014 and 2015. Spearman's correlation was performed to clarify the relationship between change of $\mathrm{HRQOL}$ and rearing behavior in migrant children. Multiple linear stepwise regression analytical methods were used to identify the variables that were associated with change of HRQOL. The results showed that total score, physical health, psychosocial health, emotional functional and social functional of HRQOL among migrant children had increased and overprotection of parents was declined. There were negative correlation between change of quality of life (total score) and change of parents rejection or mother overprotection. There were also negative correlation between change of psychosocial health and change of parents rejection and overprotection. The change of quality of life was mostly reflected by change of mother rejection. These data show that HRQOL and negative rearing behavior among migrant children had improved. The change of quality of life was most affected by the negative rearing behavior of parents, especially mothers.

\section{Introduction}

According to the Report on China's Migrant Population Development 2017, the total floating population of China has reached 245 million (Department of Services and Management of Migrant Population, National Health and Family Planning Commission of China, 2017) 1 , accounted for $17.7 \%$ of the total population at the end of 2016. The future migration of population will continue to be an important phenomenon in China's social and economic development. The familization of migration population has become more evident, and the proportion of accompanying parental migrant children aged $0-17$ is about accounted for $65 \%$ of the migrant family with children ${ }^{2}$.

Health-related quality of life (HRQOL) is a multidimensional construct that includes physical, emotional and social health dimensions, which is an important indicator of everyday functioning and any relevant reductions in these functions are critical to the child's well-being ${ }^{3}$. Several studies have demonstrated a decrease in the HRQOL in migrant children compared to urban children or rural children ${ }^{4,5}$. The main factors affecting the quality of life of migrant children included the family environment of migrant children, school environment and social environment ${ }^{6}$. From a micro perspective, the role of formal social support systems is very limited. The support of migrant children is mainly from families, classmates and 
friends ${ }^{7}$. However the parent-child relationship between migrant children and their parents is worse than that of urban children ${ }^{4}$. Migrant children have a great influence on their families education because their parents are unstable in work, their living environment is not fixed, and their families conditions are not superior ${ }^{7}$.

To promote the physical and mental health of migrant children, a number of Chinese government decrees to protect the rights and interests of migrant children have implemented. With the increasing emphasis on migrant children from all walks of life in the country and society, the education and social environment of migrant children have gradually improved ${ }^{8}$. Many schools also have carried out various activities to strengthen links between schools and families. In this study, HRQOL and rearing behavior among migrant children were measured for two consecutive years to understand their changes or improvements.

\section{Methods}

\section{Subjects and procedure}

For study purpose, migrant children are defined as children who migrated from rural to urban areas with one or both parents. Keqiao district of Shaoxing city is wellknown throughout the country as the textile industry. Its economic level is one of the top ten in the country and attracts a large number of migrant workers, the number reaches above 700 thousands. The number of families migrating with children is also increasing, their need to get public service and education in the inflow area expands increasingly. So local government set up schools for migrant children, called migrant children's school.

Data were obtained from twice survey in 2014 and 2015 in Keqiao district of Shaoxing city. The target population comprised migrant children from Chinese primary school adolescents aged 10-13, randomly selected by cluster sampling technique. All students in grade four and grade five (Since the questionnaire should be completed independently and could be follow-up), were drawn in migrant school. In each class, all of the students were recruited on the same day into the study. In 2014, more than 200 migrant children were surveyed. Because some of them left from Shaoxing to other cities with parents or returned to their places of birth. We got 149 valid questionnaires among them after second survey in 2015.

\section{Measure of health-related quality of life and rearing behavior}

Health-related quality of life was measured by The Pediatric Quality of Life Inventory Version 4.0 (PedsQL ${ }^{\mathrm{TM}} 4.0$ ) Generic Core Scales. The PedsQL ${ }^{\mathrm{TM}} 4.0$ is a 23-item questionnaire with 4 domains: physical health (8 items), emotional functioning (5 items), social functioning (5 items) and school functioning (5 items) ${ }^{9}$. Within the scales, all items are in a 5-point response scale (ranging from never a problem to almost always a problem), all are reverse-scored, and transformed to a 0-100 scale ${ }^{10}$. The physical health summary score comprised of the physical function scale, and the psychosocial health summary score comprised of the emotional, social, and school functioning scales ${ }^{11}$. The scale was translated to Chinese and validated previously, the internal consistency reliability for Total Scale Score (Cronbach's a $=0.90$ ), Physical Health Summary Score $(\mathrm{a}=0.81)$, and Psychosocial Health Summary Score $(\mathrm{a}=0.89)$ were excellent ${ }^{12}$. Higher scores indicate better HRQOL.

Short-Egna Minnenav Barndoms Uppfostran Chinese version (s-EMBU-c) was used to measure rearing behaviors. The s-EMBU-c includes father and mother version which has the same subject and content and has 23 items respectively, consisting of 23-item scale with 3 domains: rejection, emotional warmth and overprotection ${ }^{13,14}$. The coefficient of internal consistency is among $0.74 \sim 0.84$, split-half reliability is among $0.73 \sim 0.84$, and test-retest reliability is among $0.70 \sim 0.8 \mathrm{l}^{13}$.

\section{Statistical analysis}

Statistical analyses were performed using SPSS version 18.0 software, included related-samples Wilcoxon signed ranks tests for sociodemographic characteristics and paired-samples $t$-tests for HRQOL and s-EMBU-c scores. Spearman's correlation was performed to identify the relationship between change of HRQOL and rearing behavior in migrant children. Multiple linear stepwise regression was performed to assess the impact of change of HRQOL. Variables in the model included three domains of s-EMBU-c (father and mother version respectively). Variables such as change of father and mother emotional warmth and overprotection, change of father rejection were excluded by stepwise regression. The variance inflation factor (VIF) of the variable (change of mother rejection) was 1.0 in final model based on collinearity diagnositics.

\section{Results}

\section{Sociodemographic characteristics}

Data were obtained from 149 migrant children ( 91 boys and 58 girls). Their sociodemographic characteristics are shown in Table 1 . There were no significant differences in academic record, relations with classmates, self-rated health and self-rated sleeping between two measurements. Compared to the first measurement migrant children' appetite became better. $(P<0.05$, Table 1$)$.

\section{Health-related quality of life and rearing behavior}

No significant differences in school functioning was found. However total score, physical health, psychosocial health, emotional functional and social functional of HRQOL had increased $(P<0.05$, Table 2$)$. 
Table 1: Compared of sociodemographic characteristics in migrant children

\begin{tabular}{|l|c|c|c|c|c|c|c|}
\hline \multirow{2}{*}{} & \multicolumn{3}{|c|}{ Time1 } & \multicolumn{3}{c|}{ Time2 } & \multirow{2}{*}{$\boldsymbol{P}$ value } \\
\cline { 2 - 8 } & Good & Medium & Bad & Good & Medium & Bad & 47 \\
\hline Academic record & 55 & 48 & 46 & 42 & 60 & 0.057 \\
\hline Relations with classmates & 100 & 44 & 5 & 97 & 48 & 4 & 0.786 \\
\hline Self-rated health & 126 & 20 & 3 & 131 & 16 & 2 & 0.257 \\
\hline Appetite & 77 & 63 & 9 & 93 & 51 & 5 & 0.021 \\
\hline Self-rated sleeping & 91 & 43 & 15 & 103 & 36 & 10 & 0.071 \\
\hline
\end{tabular}

Table 2: Change in HRQOL and s-EMBU-c scores in migrant children (mean \pm standard deviation)

\begin{tabular}{|c|c|c|c|c|}
\hline & Time1 & Time2 & Difference & $P$ value \\
\hline \multicolumn{5}{|l|}{ PedsQL ${ }^{\mathrm{TM}} 4.0$} \\
\hline Total score & $79.21 \pm 10.10$ & $81.83 \pm 10.01$ & 2.62 & 0.003 \\
\hline Physical health & $83.03 \pm 13.61$ & $85.54 \pm 12.43$ & 2.51 & 0.026 \\
\hline Psychosocial health & $77.15 \pm 11.55$ & $79.81 \pm 11.63$ & 2.66 & 0.014 \\
\hline Emotional functioning & $67.80 \pm 18.62$ & $72.41 \pm 17.48$ & 4.61 & 0.004 \\
\hline Social functioning & $84.88 \pm 14.36$ & $88.06 \pm 12.84$ & 3.18 & 0.015 \\
\hline School functioning & $79.22 \pm 14.11$ & $79.08 \pm 13.71$ & -0.14 & 0.921 \\
\hline \multicolumn{5}{|l|}{ s-EMBU-c } \\
\hline Father Rejection & $1.73 \pm 0.56$ & $1.72 \pm 0.59$ & -0.01 & 0.815 \\
\hline Father Emotional warmth & $2.39 \pm 0.64$ & $2.45 \pm 0.62$ & 0.06 & 0.253 \\
\hline Father Overprotection & $2.20 \pm 0.44$ & $2.05 \pm 0.47$ & -0.15 & 0.001 \\
\hline Mother Rejection & $1.69 \pm 0.55$ & $1.70 \pm 0.55$ & 0.01 & 0.750 \\
\hline Mother Emotional warmth & $2.59 \pm 0.71$ & $2.62 \pm 0.65$ & 0.03 & 0.590 \\
\hline Mother Overprotection & $2.31 \pm 0.50$ & $2.21 \pm 0.50$ & -0.10 & 0.020 \\
\hline
\end{tabular}

Table 3: Correlation coefficients among change of HRQOL and s-EMBU-c scores in migrant children

\begin{tabular}{|l|c|c|c|}
\hline \multirow{2}{*}{} & \multicolumn{2}{|c|}{ PedsQL $^{\mathrm{TM}} \mathbf{4 . 0}$} \\
\cline { 2 - 4 } & Total score & Physical health & Psychosocial health \\
\hline F-EMBU-c & & & $-0.279^{* *}$ \\
\hline Father Rejection & $-0.217^{* *}$ & -0.037 & 0.071 \\
\hline Father Overprotection & 0.043 & 0.052 & $-0.171^{*}$ \\
\hline Mother Rejection & -0.129 & -0.068 & $-0.299^{* *}$ \\
\hline Mother Emotional warmth & $-0.236^{* *}$ & -0.039 & 0.011 \\
\hline Mother Overprotection & 0.008 & 0.036 & $-0.233^{* *}$ \\
\hline
\end{tabular}

$* P<0.05, * * P<0.01$

Table 4: Variables associated with change of HRQOL, revealed by multiple linear stepwise regression.

\begin{tabular}{|c|c|c|c|c|c|c|}
\hline Dependent variable & Independent variable & B & Beta & $\mathbf{t}$ & $95 \% C l$ for $B$ & VIF \\
\hline \multirow{2}{*}{ Total score } & Constant & 2.514 & & $2.885^{* *}$ & $0.791 \sim 4.237$ & \\
\hline & Change of Mother Rejection & -6.548 & -0.293 & $-3.615 * *$ & $-10.129^{\sim}-2.967$ & 1.000 \\
\hline \multirow{2}{*}{ Psychosocial health } & Constant & 2.478 & & $2.331^{*}$ & $0.376 \sim 4.579$ & \\
\hline & Change of Mother Rejection & -8.702 & -0.317 & $-3.940 * *$ & $-13.070^{\sim}-4.335$ & 1.000 \\
\hline
\end{tabular}

${ }^{*} P<0.05,{ }^{*} P<0.01 ; B$, unstandardized coefficients; Beta, standardized coefficients

Physical health: No variables were entered into the equation.

There were no significant difference in rejection and emotional warmth. However, Migrant children's overprotection was declined $(P<0.05$ for father and mother, Table 2).

There were negative correlation between change of quality of life (total score) and change of parents rejection or mother overprotection. There were also negative correlation between change of psychosocial health and change of parents rejection or parents overprotection $(P<0.05$, Table 3$)$. The change of quality of life was mostly reflected by the negative rearing behavior (mother rejection). The data are reported in Table 4.

\section{Discussion}

Since the beginning of the 21st century, with the rapid increase in the number of floating population, the Chinese government has successively issued a number of related 
policies such as "Several Opinions on Solving the Problem of Migrant Workers" and "Several opinions on deepening the construction of new urbanization" to protect the rights of the floating population. With the gradual promotion and implementation of policies, the acceptance of migrants in cities has gradually increased, and discrimination has gradually declined. Some cities with large numbers of immigrants have established schools for children of migrant workers. In our study, migrant children's school in Keqiao district of Shaoxing city paid more attention to children education, has carried out a number of activities to promote the overall health of migrant children, such as opening an "parent-child classroom", building a "electronic communication platform"(WeChat, QQ, etc), and organization "Tutor Salon" so on.

Some studies have shown that "floating" has a significant negative impact on children's quality of life ${ }^{15}$. However our study showed that the implementation of the Chinese policy and local school's program were associated with significant improvements in the PedsQL ${ }^{\mathrm{TM}} 4.0$ domain scores of total score, physical health, psychosocial health, emotional function and social functioning $(\mathrm{p}<0.05)$ (Table 2 ). The changes of boys and girls were no significant difference ( $p>0.05)$. The improvement in children's physical health and appetite is closely related to the growth of age. However psychosocial health, emotional function and social functioning have improved significantly, especially in emotional function. The results highlight the importance of policy advocacy, social environment and school education for migrant children integrate into urban life.

The results of our study that a pronounced improvement was noted in the s-EMBU-c domain scores of father overprotection and mother overprotection $(\mathrm{p}<0.05)$. However there were no significant change in parent rejection and emotional warmth (Table 2). The changes of boys and girls were also no significant difference ( $p>0.05)$.The results showed that the improvement of family education and the establishment of a good family atmosphere are still difficult. Although migrant children can live with their parents, most parents have a low income, and they have no stable place to live. They are too busy to spend a lot of time for their children to grow up. What's more, due to the particularity of family background and social status, migrant children are vulnerable to discrimination by society. Which will further force migrant children to realize the poverty of their families and the disparity in urban children, and will induce inferiority and introverted ${ }^{16}$. Previous studies have shown that the impact on family education on children's academic achievement has undoubtedly played a fundamental role. Parents are both the child's first teacher and lifelong teacher, and the status of the family in the child's mind is irreplaceable ${ }^{7}$.

A negative correlation was found between the change of
HRQOL and parent rejection and overprotection (Table3). The main factor that influenced the change of HRQOL and psychosocial health was the change of mother rejection (Table4), which was the only variable entering the equation. A migration status itself can often be postulated as a risk factor for children's mental condition, in particular migration in first generation. Furthermore, maternal harsh parenting or inadequate parental occupation was a major influence factors in migrant children's mental health ${ }^{17}$. Compared to positive rearing behavior, the improvement in negative rearing behavior including rejection and overprotection, especially mother rejection played a more important role to promote migrant children HRQOL. The occurrence of dangerous behavior was the result of the combined effects of many factors of society. Poor parenting attitudes, methods and behaviors were important factors influencing migrant children's problematic behavior ${ }^{18}$. Children with high quality parent-child relationships have fewer problems. Establish good family education and family protection to reduce child injury and improve health.

\section{Limitations}

The study only sampled one school for migrant children in some city and the sample size is not large, the results are not applicable to all aspects and could not be generalized to whole migrant children in China. The health effects of policies and school activities often take a long time, however we only track the survey for two years and it is difficult to draw long-term conclusions.

\section{Conclusions}

The findings of this study highlight the improvement of HRQOL and rearing behavior in migrant children. This analysis provides additional evidence supporting the implementation of the policy and school's program were associated with significant improvements in HRQOL. A negative correlation was found between the change of HRQOL and negative rearing behavior. The main influential factors on improvement of HRQOL (total score and psychosocial health) is the change of mother rejection.

\section{List of abbreviations}

HRQOL: health-related quality of life;

PedsQL ${ }^{\mathrm{TM}}$ 4.0: The Pediatric Quality of Life Inventory Version 4.0

s-EMBU-c: Short-Egna Minnenav Barndoms Uppfostran Chinese version

\section{Declarations}

\section{Ethics Approval and Consent to Participate}

The study was approved by the ethics committee of the Shaoxing Universtiy Medical College. The respondents were anonymous, voluntary and consent for participation. 
Written informed consent was obtained from a parent or guardian for participants under 16 years old.

\section{Consent for publication}

The manuscript contains some individual person's data (including age, gender, academic record, and so on), consent to publish was obtained from participants.

\section{Funding}

This study was supported by grants from National Social Science Fund of China (17BRK004). The manuscript was a part of results of the funded project "Research on the Influence of Social Determinants on the Health of Migrant Workers' Children and Its Mechanism". With the support of the fund, the research team completed the design, implementation, investigation, data collection, analysis and other process of the project.

\section{Authors' contributions}

HX designed and directed the study, and analysis and interpretation of data, and drafted the manuscript. WY took the responsibility of data collection. All authors read and approved the final manuscript.

\section{Acknowledgments}

We are grateful to Prof. Hao (Institute of Preventive Medicine, Zhongshan University School of Public Health) and his research team for their kind permission to use the Chinese version scale.

\section{References}

1. Department of Services and Management of Migrant Population, National Health and Family Planning Commission of China. 'Report on China's Migrant Population Development'. China Population Publishing House. 2017; 3-8

2. Sun XH, Han BX. 'Research on Mental Health of Migrant Adolescents at Home and Abroad: Visual Analysis Based on Catespace' (in Chinese) China Youth Study. 2018; (12): 67-73.

3. Puder J, Pinto AM, Bonvin A, et al. 'Health-related quality of life in migrant preschool children'. BMC Public Health. 2013; (13): 384-92.

4. Qin M, Sun JH, Yi KH, et al. 'Investigation on quality of life in children in Fengxian District of Shanghai' (in Chinese). Occupation and Health. 2017; 33(3): 381-5.
5. Zhu SY, Lin YJ, Li CZ, et al. 'An investigation on the relationship between quality of life and resilience of floating children in junior high school' (in Chinese). China modern medicine. 2017; 24(26): 147-50.

6. Zhan YL, Yang ZC, Peng Y. 'The quality of life of urban migrant children and its influencing factors' (in Chinese). Social psychology. 2009; 24(2): 43-6, 63.

7. Chen X. 'Exploring the Problems and Strategies of Family Education for Migrant Children' (in Chinese). Primary and secondary school mental health education. 2019; (2): 12-7.

8. Yang ZY, Guo PJ. 'Study on the Adaptability of Schools for Migrant Children in Beijing' (in Chinese). School Party Building and Ideological Education. 2018; (12): 91-4.

9. Doostfatemeh M, Ayatollahi SMT, Jafari P. 'Testing parent dyad interchangeability in the parent proxy-report of PedsQL ${ }^{\mathrm{TM}} 4.0$ : a differential item functioning analysis'. Quality of Life Research. 2015; (3): 931-9.

10. Knez R, Stevanovic D, Vulic'-Prtoric'A, et al. 'The Croatian Version of the Pediatric Quality of Life Inventory (PedsQL ${ }^{\mathrm{TM}}$ ) Family Impact Module: Cross-Cultural Adaptation and Psychometric Evaluation'. Journal of Child and Family Studies. 2015; 24: 363-71.

11. Varni JW, Seid M, Knight TS, et al. 'The PedsQL'TM4.0 Generic Core Scales: Sensitivity, Responsiveness, and Impact on Clinical DecisionMaking. Journal of Behavioral Medicine. 2002; 25(2): 175-93.

12. Chen YM, He LP, Mai JC, et al. 'Validity and reliability of Pediatric Quality of Life Inventory Version 4.0 Generic Core Scales in Chinese children and adolescents' (in Chinese).Chinese Journal of Epidemiology. 2008; 29(6): 560-3.

13. Jiang J, Lu ZR, Jiang BJ, et al. 'Revision of the Short-form EgnaMinnenavBarndomsUppfostran for Chinese' (in Chinese). Psychological Development and Education. 2010; (1): 94-9.

14. Arrindell WA, Sanavio E, Aguilar G, et al. 'The development of a short form of the EMBU: Its appraisal with students in Greece, Guatemala, Hungary and Italy'. Personality and Individual Differences. 1999; (27): 613-28

15. Wang HY. Current Situation and Influencing Factors of the Quality of Life of Migrant Children in China: Based on Literature Review (in Chinese). Journal of Jiangnan University (Humanities \& Social Sciences). 2019 18(2): 42-49,78.

16. Yang MW, Li Y. 'The performance of floating children's inferiority and the intervention skills of group social work methods--- an example of the $\mathrm{Q}$ project in G Community' (in Chinese). Modern Communication. 2019; (2): 52-3.

17. Kouider EB, Koglin U, Petermann F. Emotional and behavioral problems in migrant children and adolescents in Europe: a systematic review. European Child \& Adolescent Psychiatry. 2014; 23(6): 373-91.

18. Yan PC, Du HF, Zhang QC. 'Study on the Differences between Family Support and Dangerous Behaviors of Floating Children born after 2000' (in Chinese). Gansu Social Science. 2018; (4): 69-75. 